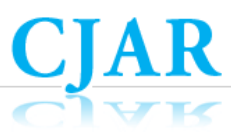

Canadian Journal of Action Research

Volume 21, Issue 1, 2020, pages 87-101

\title{
MASQUERADE OF NEOLIBERAL CONCEPTS REVEALED: SELF-REGULATION SKILLS IN ONTARIO'S FULL DAY KINDERGARTEN PROGRAM
}

\author{
Manu Sharma \\ Thompson Rivers University
}

\begin{abstract}
This study examines an action research project that included four kindergarten teachers who taught in the first year of the Ontario's mandated full day kindergarten (FDK) program, which began in September 2016. This action research project focused on the teachers' concerns about the constant unsafe violence, bullying and disruptive behaviour that characterized their FDK classrooms, which led them to explore self-regulation skills. According to the FDK program developers and school administrators, self-regulation was the key to eliminating such difficult behaviours and actions. However, the findings of the action research study revealed there were many challenges in sustaining and having students understand self-regulation, and there was a disconnect between the theoretical understanding of self-regulation and the practical reality of how self-regulation was used in the classroom. The findings of this action research study bring forth an interesting argument: the practical use of self-regulation in FDK classrooms (un)consciously gives permission to the reach and subsequent impact of neoliberalism in schools.
\end{abstract}

KEYWORDS: Action research; Full day kindergarten; Neoliberalism; Governmentality

\section{INTRODUCTION}

In 2016, Ontario decided to make all kindergarten classrooms into full day kindergarten (FDK) programs. FDK was created to support parents to return back to work (Ray \& Smith, 2010) and to give an educational head start to children (Becker \& Mastrangelo, 2017; Ray \& Smith, 2010; Warburton, Warburton \& Hertzman, 2012). The FDK program entailed a great deal of change from what the province previously had in place. Prior to September 2016, most public schools offered a half day program for junior kindergarten in the morning (10-12 four-year-old students), and a half day program for senior kindergarten in the afternoon (10-12 five-year-old students) (Early Childhood Education and Care in Canada, 2008, p. 69). This old model of half-day kindergarten programs was supported by a 
full time kindergarten teacher and a general educational assistant. However, since September 2016, FDK offers uncapped classroom sizes, a kindergarten teacher and a certified early childhood educator, and students aged four and five are mixed into one classroom. There have been many articles in the literature on the benefits and challenges this new FDK program brings.

What we saw in our classes, when we first started discussing the possibility of a project, was violent behavior, constant outbursts from students, and a lack of understanding of emotion and how students responded to conflict. We wanted to know how could we address these concerns consistently in our classrooms. FDK teachers were expected to assess and use self-regulation to address inappropriate behaviour and actions in the classroom setting, but teachers struggled to understand how to teach self-regulation. Three FDK teachers and myself identified this as the main challenge and the basis for this action research project: How to teach and assess self-regulation skills. In other words, we were expected to use self-regulation to eliminate in-class fighting, bullying, and aggressive behaviour. However, through reflection and analysis in this action research project, questions and concerns have emerged regarding the integration of self-regulation within FDK context. In particular, I have noticed that self-regulation practices as part of FDK match neoliberal traits that have become predominant in education today. Therefore, this paper both reports on the action research project and analyzes its subject - self-regulation - through a critical consideration of neoliberalism in schools.

\section{LITERATURE REVIEW}

\section{Understanding Self-Regulation}

To better understand the term self-regulation, it is important to briefly visit the origins of self-regulation, what it means, and how FDK teachers are currently introduced to it. The origins of self-regulation lie in the field of psychology dating back to Vygotsky's notion of transformation from basic to higher functions through self-regulation processes (Díaz, Neal, \& Amaya-Williams, 1990). Many other well-known psychologists have studied selfregulation, such as Albert Bandura, Dale Schunk, and Roy Baumeister. Psychologists have used self-regulation techniques to help address disorders such as depression and risktaking behaviours, and in general to help patients with a number of health problems (Knittle, Maes, \& De Gucht, 2010; Raffaelli \& Crockett, 2003; Weidner, Sieverding \& Chesney, 2016). Given this psychology-based background and context, what does selfregulation have to do with kindergarten? I wondered if this meant there were social and psychological concerns that become emergent at young ages, and instead of receiving help from psychologists, it was expected that school teachers do this work.

As I conducted a literature search on self-regulation, five common themes emerged: (1) behavioural self-regulation leads to academic success in literacy; (2) gender and selfregulation; (3) socio-economic status and self-regulation; (4) different domains of selfregulation; and (5) time and self-regulation. Each theme is briefly described below. 


\section{(1) Behavioural self-regulation leads to academic success in literacy}

Although some studies argue academic success is related to students' ability to effectively self-regulate, there are also studies that demonstrate no academic gains can be attributed to students who self-regulate well. Both Gestsdottir et al.'s (2014) study on behavioural self-regulation and Tominey and McClelland's (2011) study revealed a positive connection to academic growth, and specifically showed gains in letter and word recognition skills. The general logic in both of these studies was: If a child is more focused and calm, they will learn literacy skills more efficiently and successfully. Moreover, Montroy et al. (2014) claim that children with low self-regulation skills exhibit temper tantrums and bullying traits, which often resulted in fewer literacy learning opportunities because educators were less likely to engage in teaching activities with difficult students. Thus, Montroy et al. (2014) argue that literacy skills were taught more effectively and frequently to students who demonstrated stronger self-regulation skills. Furthermore, von Suchodoletz et al. (2013) suggest that behavioural self-regulation is important to children's development because it can help to increase attention, memory, and inhibitory control skills that are needed for first grade and therefore narrow the academic achievement gap that exists at school entry. In contrast, a recent study based on data from 32,027 senior kindergarten students in Ontario gathered from the 2012 Early Development Instrument, demonstrated the connection between self-regulation and numeracy was found to be slightly negative, and high levels of self-regulation did not have any effects on literacy learning (Youmans, Kirby, \& Freeman, 2018).

\section{(2) Gender and self-regulation}

There were some international empirical studies that investigated how students perform on simple and more complex activities, and the performance outcomes were separated by students' gender. Please note there is often an assumption about gender matching the sex of the student in the literature reviewed. In a study in Iceland, Gestsdottir et al. (2014) noticed that during an exercise entitled Heads, Toes, Knees and Shoulders (HTKS) young females were out-performing their male peers. The local teacher's assessments of students' ability to self-regulate behaviour demonstrated the same gendered trend, in which the females out-performed the male students (Gestsdottir et al., 2014). The reason posited for why female students were doing better than males was that children in Iceland start preschool earlier than other countries such as France and Germany, and because Icelandic students often spend more time interacting with their older, same-gendered peers. Similarly, Matthews, Ponitz and Morrison (2009) conducted a study in America that concluded girls did better on the HTKS task throughout the school year. Even though it was noted that the boys improved their score over the term, they did not outperform the girls.

Lastly, there was an American study that examined not only the behavioural regulation according to gender but also in relation to literacy outcomes. In this study, Montroy et al. (2014) found that gender did not impact the way social skills were developed, nor did it show how self-regulation led to improvements in literacy. 


\section{(3) Socio-economic status and self-regulation}

In general, students who came from low socio-economic backgrounds had difficulty selfregulating due to various factors that can be connected back to environmental and nurture based factors, such as, but not limited to, time with parents to create a strong bond, parental guidance on how to de-escalate heightened emotions, the level of safety in the home, and the presence of a supportive and reliable family structure (Blair \& Raver, 2015). Blair and Raver (2015) claim that children in poverty have less access to higher-quality care outside the home, and a significantly lower probability of attending preschools that are emotionally and cognitively supportive for optimal self-regulation. As a result, children in poverty have fewer opportunities to engage in learning activities, such as learning to read and developing varied language that promotes literacy and vocabulary development.

Miech, Essex and Goldsmith (2001) argue that socio-economic background impacts how teachers and peers interact in kindergarten. At times, teachers label students from low socio-economic backgrounds as hyperactive-attention deficient, and this has implications on how their current and future scholastic ability are assessed by teachers. Moreover, Miech, Essex and Goldsmith (2001) argue that interpersonal challenges are consistently heightened among children from lower socio-economic backgrounds because they have lower self-regulation skills. Thus, this study further supported the connection between lower socio-economic backgrounds and low self-regulation abilities. Similarly, Tominey and McClelland's (2011) findings indicate that participants from low-income families achieved lower behavioural self-regulation gains than their peers. Students from highincome families showed the most significant improvements during circle time activities.

\section{(4) Different domains of self-regulation}

Often articles that discussed self-regulation in kindergarten classrooms also referenced different understandings of self-regulation, which evolved from different domains. There are a wide range of domains that are part of understanding self-regulation such as, but not limited to, behavioural, cognitive, social, emotional, biological, and prosocial domains. Considering this wide range of domains, it would seem that scholars expect self-regulation to be understood as a complex and multi-faceted concept, which again begs the question of how this can be addressed in kindergarten classrooms.

Willoughby et al. (2011) discussed the emotional domain of self-regulation by drawing on what they label as hot regulatory tasks. These tasks involve solving new problems that arouse emotions, and include activities that require effort and control or that have appetitive requirements. In contrast, they also researched the cognitive domain of selfregulation that they thought engaged the orbitofrontal cortex of the brain, by drawing on what they label as cool regulatory tasks. Cool regulatory tasks involve solving new problems that are emotionally neutral. This research on the emotional and cognitive domains of self-regulation showed that students' performance on self-regulation activities were better captured using a hot versus cool model than a model that was undifferentiated. (Willoughby et al., 2011). 
Similarly, Ursache, Blair and Raver (2012) explored the same domains of emotion and cognition, but their research uncovered a bidirectional model that helps explain selfregulation development. Their model examines the relationship between the development of executive functioning skills and the development of emotion regulation. It views the cognitive and emotional sides of self-regulation as being reciprocal rather than separate. Thus, in the studies by Willoughby et al. (2011) and Ursache, Blair and Raver (2012), the tasks used to assess self-regulation have different models of causation impacting the findings of self-regulation skills in students. This calls into question the reliability of assessing self-regulation in kindergarten.

Shanker (2013) posits five domains to self-regulation: biological, emotional, cognitive, social, and prosocial. In his textbook, he draws upon Roy Bameister and Kathleen Vohs' (2011) Handbook of Self-Regulation: Research, Theory, and Applications, in which each of the five domains are connected, respectively, to:

1. Attain, maintain, and change one's level of energy to match the demands of a task or situation; 2. Monitor, evaluate, and modify one's emotions; 3. Sustain and shift one's attention when necessary and ignore distractions; 4. Understand both the meaning of a variety of social interactions and how to engage in them in a sustained way; 5. Connect with and care about what others are thinking and feeling-to empathize and act accordingly. (Shanker, 2013, p. xii)

\section{(5) Time and self-regulation}

The last theme of time and self-regulation addresses when self-regulation skills can be introduced and how long it takes to develop them. One study suggested it takes about two to three years for children to progress from following basic self-regulating instructions to complex, abstract ones like those in the HTKS task (Montroy et al., 2016). This study's findings are based on the researchers considering a variety of factors such as gender, language skills, and the mother's education level, as they believed these factors to be important in determining the exact age at which following the self-regulation progression occurs (Montroy et al., 2016).

In contrast, Tominey and McClelland (2011) argue that self-regulation skills can be developed in children before they enter kindergarten. In this study they explore the effectiveness of implementing circle time games to improve children's behavioural selfregulation during the year prior to kindergarten. During the year before kindergarten, the researchers discover it is possible to build self-regulation skills. What remains unclear is how self-regulation is defined because the definition will impact the expected time line to attain self-regulation skills. Moreover, given the differing definitions and domains, how does self-regulation emerge as a skill? And lastly, how is such a skill measured and assessed in kindergarten students?

\section{FDK Teachers and Learning about Self-Regulation Theory}

As an FDK teacher, I wanted to learn more about self-regulation so I signed up for a professional development session on this topic. At the professional development session, I 
received a copy of Calm, Alert, and Learning: Classroom Strategies for Self-Regulation written by Stuart Shanker in 2013. Shanker (2013) explains how self-regulation is modeled in a five-domain model, as mentioned above, under the heading of Different domains of selfregulation. I still recall feeling stuck after hearing about the many things that can be accomplished by self-regulation, and not truly understanding what self-regulation was and how I was expected to teach and assess it. In the professional development session, a great deal of positive success stories were shared by the person leading the session, emphasizing the importance of recognizing all five domains. In retrospect, the biggest missing piece in the professional development session were the unsuccessful stories and what to do when children who are introduced to self-regulation materials do not sustain the practices, or even disrupt the path of other students' self-regulation choices. And secondly, how was it possible to cover all five domains in the current uncapped and inclusive Ontario FDK classroom? It seemed unrealistic and inauthentic. As a result, myself and three other FDK teachers decided to embark upon an action research study on self-regulation with the hope of implementing it in FDK classrooms to address unsafe play, violence and bullying.

\section{Methodology AND Methods Action Research}

This paper uses practitioner based action research methodology (Cochran-Smith \& Lytle 2015; Tomal, 2010) in which four FDK teachers (including myself) collaboratively identified a classroom problem, then researched how to address it, implemented the knowledge and practices we found in our classrooms and then repeated the implementation process with modifications to reach desired outcomes with their coteaching colleagues.

The methods in this practitioner based action research study used to collect data included: classroom observations and behavioural logs, reflections on dialogue before and after coteaching, and several planning and debriefing meeting minutes over the course of one school year. In particular, class observations were logged daily into teacher journals and behavioural/communication logs for particular students who had difficulty transitioning into the FDK environment. These logs were used to inform this study. Due to privacy reasons, the content of these journals and logs are not directly shared in this article, but rather what is reported are the themes that emerged in conversation among the four teachers. With respect to the dialogue before and after co-teaching about self-regulation, emails and phone conversations were exchanged amongst the teachers involved in this process, as well as private conversations before and after the school day. Lastly, the planning and debriefing meetings that happened involving the four core FDK teachers were used as a platform to consolidate issues and themes that emerged from email communication, phone conversations, and meetings in the school about self-regulation.

As kindergarten teachers who were adjusting to the new FDK program in Ontario, we decided to do an action research project to improve our classroom environment. The four of us met initially during a lunch break and discussed what troubled us the most about the FDK program in our classrooms: the level of unsafe violence, disruptive outbursts, and inappropriate behaviours. After discovering we all had the same concerns, we discussed 
possible recommendations and ways to address these concerns, and we decided we wanted to understand and apply self-regulation. As a result, we applied and received a modest grant with the Ontario Teacher Federation.

With the financial aid of the grant, we were able to have release time from our teaching duties and had meetings to help explore ideas and resources to support teaching about selfregulation in our FDK classrooms. We bought and summarized different reading material and found websites with recommended activities, equipment, music and videos. Consequently, we devised a lesson plan to teach self-regulation skills to FDK students with the purchased equipment for the classroom. We adapted the language, equipment, activity and lesson time frame to meet the needs and interests of our students. After engaging with our lesson plans in our respective classrooms, we realized that we had to tweak the lesson plan, and we wanted to offer it to the remaining 3 FDK classrooms in the school. We reached out to our FDK colleagues and organized a time to co-teach about self-regulation in their respective classroom spaces, again with small adaptations to meet the needs of those classrooms and taking into consideration our colleagues' input about the lesson plan. Thus, after doing two rounds of teaching a lesson on self-regulation, we re-assessed and reflected on how impactful these two rounds of action research had been in our respective classrooms by consulting our FDK colleagues on their thoughts and reflecting on what we thought worked and what was still a challenge.

\section{School Site Context}

The school site consisted of five English speaking FDK classrooms and two French speaking FDK classrooms. The students came from various backgrounds, including Korean, Jewish, Filipino, and Russian, and were often encountering their first structured environment. Shifting from their home environment to the school classroom environment is often a significant transition for many students. We realized this transition is further complicated for children with special needs entering into an FDK program.

In 2016, we had approximately 30 kindergarten students across the FDK classrooms who were identified with special needs, in particular, students on the autism spectrum. As educators, we recognized the importance of inclusion and creating an environment in which all students can feel accepted, safe, and empowered.

We also acknowledged the practical reality of the new FDK program, which has uncapped classroom sizes, and limited material and human resources. We knew that it takes a great deal of time, compassion, and care to support each student's personal development journey in kindergarten. Thus, our research project examined how different practices of selfregulation could develop a sense of well-being in the FDK classroom so that all students can attain a positive developmental journey in kindergarten. We wanted to answer the following research questions:

1. What self-regulation techniques and activities can be employed to create a safe and inclusive learning environment for all students?

2. How do such self-regulation skills help (if at all) with the overall well-being of the students? 
3. What are some of the challenges or gaps in implementing self-regulated/self-control practices?

4. Why are self-regulation/self-control practices vital (if at all) for FDK classrooms?

\section{Co-Teaching and Learning Together with our Colleagues}

We enjoyed reviewing and exploring different resources purchased to support our project. We learned some techniques from online sources and some from physical materials. After discussing and examining resources, we determined a plan that fit within our budget. We were able to put together seven resource bins for seven FDK classes in our school.

The contents of each resource bin were:

- Labels

- A visual feelings chart and companion choice board

- The Feelings Book by Todd Parr (2000)

- Six different sensory timers and liquid toys

- A mirror

- Eight magnets

- A magnifying glass

- A soft ball

- Sensory balls

- Blue tack

- An exercise band

- A larger feeling poster with visual images

We used these resources along with the co-teaching lesson plan we designed to help disseminate our findings about self-regulation practices and techniques to our colleagues.

The following is the lesson plan we designed, and it could be a good resource for other teachers who are looking to start implementing self-regulation practices in their FDK classrooms. In addition to the provided lesson plan, we also shared online websites and tools that could help foster an understanding self-regulation for teachers and students in class.

\section{RESULTS}

This action research project attempted to teach about self-regulation and self-regulation practices in seven FDK classrooms. While partly completed, the findings that emerged from this action research project yielded unexpected outcomes based on several challenges, which meant we were unable to address each of the original four research questions that were seeking effective practices for teaching self-regulation. 
We learned that a co-teaching lesson like the one we prepared should be done earlier in the year to help set the tone of the classroom. One key insight was that students respond better to understanding "self-control" instead of "self-regulation", and so we adapted this in our co-teaching lesson even though our research was informed by an exploration of selfregulation. In hindsight, we reflected that in our classrooms we were not using selfregulation in its pure form (i.e., in the psychologically informed meaning of the term), but as self-control since this term was better understood by students and teachers than selfregulation.

We also received feedback from those who participated in co-teaching that a lot of practice needs to happen to maintain the use of self-regulation techniques, and this not be possible as the "newness of the resources" disappears. In addition, many concerns were raised about the overall challenges with FDK classes such as class size, classroom space, professional training and opportunities to learn about self-regulation, support from administration, collaboration with parents, and classroom budgets.

Another key concern was that students with special needs might require further support with self-regulation, especially for those who do not comprehend inferences, emotions, and their impact on other students or adults in the classroom. For example, students who are on the autism spectrum disorder continuum or those with anger/violent behaviours in FDK classrooms may present challenges that require other professionals to assist with greater equity and learning concerns before self-regulation techniques can be successfully implemented.

Nevertheless, the silver lining in this action research project was that we learned a lot about the theory of self-regulation. We appreciated what self-regulation theories aspire to do, and we are glad that as teachers we could test it out in the practical realities of our classrooms and our colleagues' classrooms. For us, this action research project offered insight on how the implementation of self-regulation morphed the multiple theoretical approaches to self-regulation into something very different in the FDK classroom. This morphed image expected kindergarten students to gain self-control, with the understanding that teachers would expose students to identifying their emotions, and reassessing what they could do to bring their emotions into a neutral position. In other words, we felt that teachers and the school were looking at self-regulation practices to help address unsafe violence, bullying and disruptive behaviour in this newly developed FDK program. Unfortunately, despite what we expected to accomplish by doing this action research study, we are still hopeful that the resource bins we provided to FDK classrooms will be further explored by teachers and their students.

\section{Discussion}

Reflecting on what emerged from the literature search and the outcomes of our action research study, I argue there is a strong undertone of neoliberalism in how self-regulation is understood and used in an FDK classroom space. To better understand and discuss the presence of neoliberalism when thinking about self-regulation in the FDK space, it is important to understand what neoliberalism means with respect to education. 


\section{Neoliberalism and Neoliberal Concepts Revealed}

Neoliberalism promotes a capitalist mindset that is cloaked in the masquerade of concepts such as individualism, accountability, equal rights, standardization and privatization (Harvey, 2005). The neoliberal ideology gives a false image of freedom when in reality many things are under close surveillance and controlled by institutional regimes, such as in education or business trades.

For the purposes of this paper, I first examine the current neoliberal influence on education by connecting it back to my action research study findings. I will explain that when the complexity of self-regulation is reduced to self-control in FDK classrooms, what is really at work is the influence of neoliberalism to simplify and regulate education. While drawing these connections between the practical reality and neoliberalism, I will support my claims with theme four and five that emerged from the literature on self-regulation and kindergarten (different domains of self-regulation, and the time commitment). Furthermore, I will examine the neoliberal concepts of accountability, standardization and equal rights in relation to the first three themes of the literature on self-regulation and kindergarten (achievement, gender, and socio-economic status).

\section{Current Neoliberal Influence on Education}

Kuntz and Petrovic (2011) summarized central characteristics of neoliberal influence on education:

Contemporarily, the legitimate frame is neoliberalism, which grants little virtue to multidimensionality, supporting, instead, a flattening out of educational practice that foregrounds issues of efficiency and predefined accountability. Further, this frame compels educational formations that privilege rigidly standardized mechanisms for defining student and institutional success, economic substantiations for educational meaning, and a conflation of democracy with capitalism. A neoliberal frame asserts conceptual metaphors of, for example, production and the corporate mentality of measurable inputs and outputs that hail education as generating a set of skills useful in the production of work. (p. 181)

Hyslop-Margison and Sears (2006) also observed that "public education in the neo-liberal order, then, is simply one component of a larger economic system, and the focus of education policy and curriculum development is directed accordingly" (p. 13).

As described above, self-regulation is a multidimensional notion that encompasses several domains, including behavioural, emotional, social, cognitive, and prosocial (Shanker, 2013). However, under neoliberalism and in the context of FDK, this multidimensionality and complexity of self-regulation is flattened and reduced mostly to the behavioural dimension, and as such transformed to a mechanistic technique aimed at controlling students' behaviour. Thus, promoting self-regulation in students, especially young students such as in kindergarten, might dangerously divert to a form of governmentality (Foucault, 1991). Governmentality is internalization and following of forms of knowledge and power structures that underlie neoliberalism (Lambeir \& Ramaekers, 2008; Peters, 2002; Sleeter, 2008). As such, governmentality is a more efficient form of social control compared to, for 
example, direct tyranny, as knowledge enables individuals to govern themselves. Instead of investing resources in controlling the population, governmentality causes individuals to control themselves in ways desired by authorities (such social control, of course, also diminishes rejection).

What I argue is that when a simplified, impoverished version of self-regulation is implemented in FDK, self-regulation can - and does - become a form of neoliberal governmentality. This impoverished version of self-regulation naturally emerged in the action research study given the current neoliberal influence on education. As a result, selfregulation mainly becomes a tool to make students internalize what is expected from them to do and how to behave in the kindergarten classroom in times of emotional difficulties. However, I argue there needs to be a genuine interactive process in which the teacher and student unpack and develop a deeper understanding of emotions and their implications on contextual situations over time. It is important to note that the time required to attain selfregulation skills based on the fifth theme of the literature is still debated; it cannot necessarily be managed or 'completed' in the two year framework of kindergarten.

In light of our action research study, it is clear there is limited teacher training on understanding, teaching and assessing self-regulation skills within FDK. Teachers might and I argue that many times they actually do - use students' self-regulation practices as a control tool to better manage the classroom rather than as a technique in the students' disposal to handle their mental and emotional situations. Thus, self-regulation becomes another (and one might say, simple and sophisticated) form of social control where individuals, FDK students in this case, govern themselves in favour of an institutional interest (and ultimately broader social and economic interests). As a result, self-regulation, perhaps intentionally, promotes governmentality. In another words, self-regulation becomes a way to make students to be regulated from "inside" (Peters, 2002). The mentalemotional work entailed in this impoverished version of self-regulation is used for creating "responsibilized subjects" (Davies \& Bansel, 2007) who are "trained" to keep their mentalemotional problems for themselves without requiring a great deal of teacher intervention.

\section{Neoliberal Concepts of Accountability, Standardization, and Equal Rights}

The FDK program emphasizes the need to teach and assess self-regulation skills. Based on the first thematic literature finding (achievement of literacy if a student has high selfregulation skills), there are some scripted tests such as the HTKS that are used to measure the student's level of self-regulation skill. These are then used to provide the baseline in research and report cards that assess this skill. In neoliberalism, the concept of accountability can be applied to how self-regulation has been made into a skill that needs to be required and assessed (Barnhart, 2018; De Lissovoy, 2013). First, FDK programs have exercised accountability practices through the emphasis on self-regulation skills by teaching and assessing them. Secondly, the finding of mixed results that demonstrate that literacy success is sometimes connected to how well a student self-regulates is connected to the neoliberal concept of accountability. Instead of examining different levels of engagement and areas of interest in literacy development through frequent interaction between teacher and student, the neoliberal concept of accountability shifts the 
accountability to the individual for their own literacy development via their self-regulation skills. In other words, if students can train themselves to attain high self-regulation skills, then they will achieve high literacy development, thus they are accountable for their success. This level of individual accountability gives permission to simplify the complex level of interaction and process of learning that occurs in FDK classrooms.

The second thematic literature finding (the relationship between gender and selfregulation skills) illustrates there are differences how females and males attain selfregulation skills. However, because neoliberalism does not acknowledge individual differences and how they impact access to exercising equal rights, it overlooks such social justice issues. If there is a gap between how different genders learn, then it needs to be addressed before providing a standardized assessment and standardized practices that teach the skill of self-regulation.

Similarly, the third thematic literature finding (the relationship between socio-economic status and self-regulation skills) challenges the neoliberal concept of equal rights to education. The literature revealed that students who come from low socio-economic backgrounds have lower self-regulation skills. However, there is no space to address the gap that may exist for some students impacted by different socio-economic backgrounds because teachers are expected to teach and assess these skills in a standardized way. The multiple dimensions of identity are important as it allows us to understand who a student is and how their identity may impact their schooling experience; however, this is not considered in a neoliberal context of education. Thus, the current neoliberal context of education eliminates the complexity of a student's identity and the interactivity of it in the process of learning. A teacher should aspire to support each student's individuality instead of teaching standardized skills in standardized ways, and then assessing the student with standardized assessments.

\section{CONCLUSION AND Future RESEARCH}

As kindergarten classrooms become more impacted by neoliberal scripted and standardized curriculum expectations that aim for self-regulation skills to become internalized by students, educators become (un)knowingly complicit in supporting a neoliberal governmentality approach to education. Consequently, there is a grave danger that young minds will become susceptible to a larger neoliberal framework. As it is normalized, this framework could gain more control on school systems. To ensure standardization and accountability in the current context of neoliberalism in kindergarten classrooms, all students, regardless of their different identities, are "taught and assessed" on self-regulation as a skill, albeit an overly simplistic and mechanistic version of it. Thus, unconsciously, students are then seen as pawns that are deeply ingrained in the (in)visible larger process of neoliberalization of schools, which has damaging implications to their self-identity, autonomy, and potential aspirations to transform our society. 


\section{REFERENCES}

Barnhart, J.P. (2018). Exacerbating inequality: Public schooling in the era of neoliberal standardization. Unpublished PhD thesis. New York, NY: City University of New York.

Becker, K., \& Mastrangelo, S. (2017). Ontario's early learning-kindergarten program: A transformative early childhood education initiative. YC Young Children, 72(4), 17-23.

Blair, C., \& Raver, C.C. (2015). School readiness and self-regulation: A developmental psychobiological approach. Annual Review of Psychology, 66, 711-731. https://doi.org/10.1146/annurev-psych-010814-015221

Cochran-Smith, M., \& Lytle, S. L. (2015). Inquiry as stance: Practitioner research for the next generation. New York, NY: Teachers College Press.

Davies, B., \& Bansel, P. (2007). Neoliberalism and education. International Journal of Qualitative Studies in Education, 20(3), 247-259.

De Lissovoy, N. (2013). Pedagogy of the impossible: Neoliberalism and the ideology of accountability. Policy Futures in Education, 11(4), 423-435.

Díaz, R., Neal, C., \& Amaya-Williams, M. (1990). The social origins of self-regulation. In L. Moll (Ed.), Vygotsky and Education: Instructional Implications and Applications of Sociohistorical Psychology (pp. 127-154). Cambridge, UK: Cambridge University Press. doi:10.1017/CB09781139173674.007

Foucault, M. (1991). Governmentality. In G. Burchell, C. Gordon, and P. Miller (Eds.), The Foucault Effect: Studies in Governmentality (pp. 87-104). Chicago, IL: University of Chicago Press.

Gestsdottir, S., von Suchodoletz, A., Wanless, S.B., Hubert, B., Guimard, P., Birgisdottir, F., Gunzenhauser, C., \& McClelland, M. (2014). Early behavioral self-regulation, academic achievement, and gender: Longitudinal findings from France, Germany, and Iceland. Applied Developmental Science, 18(2), 90-109. https://doi.org/10.1080 /10888691.2014.894870

Early Childhood Education and Care in Canada (2008). Report. Childcare Canada. https://www.childcarecanada.org/publications/ecec-canada/09/11/early-childhoodeducation-and-care-canada-2008

Harvey, D. (2005). A brief history of neoliberalism. New York, NY: Oxford University Press.

Hyslop-Margison, E.J., \& Sears, A.M. (2006). Neo-liberalism, globalization and human capital learning: Reclaiming education for democratic citizenship. Springer.

Knittle, K., Maes, S., \& De Gucht, V. (2010). Psychological interventions for rheumatoid arthritis: Examining the role of self-regulation with a systematic review and metaanalysis of randomized controlled trials. Arthritis care \& research, 62(10), 1460-1472. 
Kuntz, A.M., \& Petrovic, J.E. (2011). The politics of survival in foundations of eduation: Borderlands, frames, and strategies. Educational Studies: A Journal of the American Educ Studies Association, 47(2), 174-197.

Lambeir, B., \& Ramaekers, S. (2008). Humanizing education and the educationalization of health. Educational Theory, 58(4), 435-446. https://doi.org/10.1111/j.17415446.2008.00298.x

Matthews, J.S., Ponitz, C.C., \& Morrison, F.J. (2009). Early gender differences in selfregulation and academic achievement. Journal of Educational Psychology, 101(3), 689704. https://doi.org/10.1037/a0014240

Miech, R., Essex, M.J., \& Goldsmith, H.H. (2001). Socioeconomic status and the adjustment to school: The role of self-regulation during early childhood. Sociology of Education, 74(2), 102-120. https://doi.org/10.2307/2673165

Montroy, J.J., Bowles, R.P., Skibbe, L.E., \& Foster, T.D. (2014). Social skills and problem behaviors as mediators of the relationship between behavioral self-regulation and academic achievement. Early Childhood Research Quarterly, 29, 298-309. https://doi.org/10.1016/j.ecresq.2014.03.002

Montroy, J.J., Bowles, R.P., Skibbe, L.E., McClelland, M.M., \& Morrison, F.J. (2016). The development of self-regulation across early childhood. Developmental Psychology, 52(11), 1744-1762. https://doi.org/10.1037/dev0000159

Peters, M.A. (2002). Foucault and governmentality: Understanding the neoliberal paradigm of education policy. School Field, 12(5/6), 59-80. http://eprints.gla.ac.uk/2182/

Raffaelli, M., \& Crockett, L.J. (2003). Sexual risk taking in adolescence: The role of selfregulation and attraction to risk. Developmental psychology, 39(6), 1036.

Ray, K., \& Smith, M.C. (2010). The kindergarten child: What teachers and administrators need to know to promote academic success in all children. Early Childhood Education Journal, 38, 5-18. https://doi.org/10.1007/s10643-010-0383-3

Shanker, S. (2013). Calm, alert and learning: Classroom strategies for self-regulation. Toronto: Pearson Canada.

Sleeter, C. (2008). Equity, democracy, and neoliberal assaults on teacher education. Teaching and Teacher Education, 24, 1947-1957. https://doi.org/10.1016/ j.tate.2008.04.003

Tomal, D. R. (2010). Action research for educators. Rowman \& Littlefield Publishers.

Tominey, S.L., \& McClelland, M.M. (2011). Red light, purple light: Findings from a randomized trial using circle time games to improve behavioral self-regulation in 
preschool. Early Education and Development, 22(3), 489-519. https://doi.org/10.1080/10409289.2011.574258

Ursache, A., Blair, C., \& Raver, C. C. (2012). The promotion of self-regulation as a means of enhancing school readiness and early achievement in children at risk for school failure. Child Development Perspectives, 6(2), 122-128. https://doi.org/10.1111/j.17508606.2011.00209.x

Vohs, K.D., \& Baumeister, R.F. (2011). Handbook of self-regulation: Research, theory, and applications (2nd ed.). Guilford Press.

von Suchodoletz, A., Gestsdottir, S., Wanless, S. B., McClelland, M. M., Birgisdottir, F., Gunzenhauser, C., \& Ragnarsdottir, H. (2013). Behavioral self-regulation and relations to emergent academic skills among children in Germany and Iceland. Early Childhood Research Quarterly, 28, 62-73. https://doi.org/10.1016/j.ecresq.2012.05.003

Warburton, W.P., Warburton, R.N., \& Hertzman, C. (2012). Does full day kindergarten help kids? Canadian Public Policy, 38(4), 591-603. https://doi.org/10.3138/CPP.38.4.591

Weidner, G., Sieverding, M., \& Chesney, M.A. (2016). The role of self-regulation in health and illness. Psychology, Health \& Medicine, 21:2, 135-137, DOI: 10.1080/13548506.2015.1115528

Willoughby, M., Kupersmidt, J., Voegler-Lee, M., \& Bryant, D. (2011). Contributions of hot and cool self-regulation to preschool disruptive behavior and academic achievement. Developmental Neuropsychology, 36(2), 162-180. https://doi.org/10.1080/ 87565641.2010.54998

Youmans, A.S., Kirby, J.R., \& Freeman, J.G. (2018). How effectively does the full-day, playbased kindergarten programme in Ontario promote self-regulation, literacy, and numeracy? Early Child Development and Care, 188(12), 1788-1800. https://doi.org/10.1080/03004430.2017.1287177

\section{BiOgRAPHICAL Note:}

Manu Sharma is an Assistant Professor at Thompson Rivers University in the Faculty of Education and Social Work, where she teaches foundational courses in the Masters of Education program. Dr. Sharma has previously taught a variety of undergraduate and graduate courses and supported field placements at University of Wisconsin-River Falls, Brock University, University of Toronto, and University of Windsor. She also worked for the Toronto District School Board and in international settings as a public educator. Her research interests and publications in the field of education are based on equity initiatives, teacher development, social justice pedagogy, deficit thinking, and international teaching experiences. Recently she published a co-authored book (2020), "Educators for Diverse Classrooms: A Case Study approach to Equity and Inclusion in Education." 